\title{
IPSS-R Risk Category Intermediate
}

National Cancer Institute

\section{Source}

National Cancer Institute. IPSS-R Risk Category Intermediate. NCI Thesaurus. Code C162682.

A total IPSS-R score of 3.5 to 4.5 , indicating intermediate risk. 